
\title{
R Reserach S Suare \\ The influence of microplastics on the toxic effects and biodegradation of bisphenol A in the microalgae Chlorella pyrenoidosa
}

\section{Dandan He}

Southwest University

\section{Youmei Zeng}

Southwest University

Guangming Zhou ( $2847109380 @ q q . c o m$ )

Southwest University https://orcid.org/0000-0001-5334-3662

\section{Research Article}

Keywords: Biodegradation, Bisphenol A, Chlorella pyrenoidosa, Micoplastics

Posted Date: January 26th, 2022

DOI: https://doi.org/10.21203/rs.3.rs-1259089/v1

License: (c) (i) This work is licensed under a Creative Commons Attribution 4.0 International License.

Read Full License 


\section{Abstract}

Bisphenol A (BPA) and Polystyrene (PS) microplastics have attracted much attention due to they were widely distributed in the environment, while their combined toxicity to aquatic organisms has rarely been studied. Therefore, this study explored that the impact of microplastics on the toxic effects and biodegradation of BPA to the microalgae Chlorella pyrenoidosa (C. pyrenoidosa). The results indicated that the presence of PS increased the growth inhibition of BPA and also accelerated the degradation efficiency of BPA in the medium of $C$. pyrenoidosa. When PS and BPA coexisted, the chlorophyll content and the Fv/Fm value decreased with the increased PS concentration due to the hermetic effect and shading effect. Moreover, this study also found that five intermediates were formed during BPA degradation process because of the presence of oxidoreductase and glycosyltransferase. The results of the study provided vital information on the effect of PS on the toxicity and biodegradation of BPA to microalgal.

\section{Introduction}

Microplastics are defined as a particle size less than $5 \mathrm{~mm}$, which is a new type of environmental pollutant with stable chemical properties and refractory to degradation (Horton et al. 2017; Lin et al. 2020). Microplastics can be discharged into the water environment in many ways, such as direct discharge of cosmetics or fine fibers into the water during industrial production and human daily life (Herbort et al. 2018). Because of their low price and easy processing, plastics play a vital role in packaging, construction, transportation, electric power, medical devices and other fields, and have been widely used in daily life (Yang et al. 2020b). Microplastics are widely distributed in water and exist in many forms. Polypropylene (PP), polyethylene (PE), polystyrene (PS), polyvinylchloride (PVC), and polyamide (PA) were the most common types of microplastics found in the freshwater systems, marine environments and sediments (Cincinelli et al. 2017; Klein et al. 2015).

Previous studies have shown that microplastics may have a variety of negative effects on the aquatic environment. For example, microplastics can reduce energy intake and affect the fecundity and offspring performance of aquatic organisms (Sussarellu et al. 2016). Wu et al. investigated different sizes ( $1 \mu \mathrm{m}$ and $100 \mathrm{~nm}$ ) of the PS microplastics on the effect of the algae growth, the results indicated that $1 \mu \mathrm{m}$ microplastics showing more adverse effects than $100 \mathrm{~nm}$ microplastics to Microcystis aeruginosa (Wu et al. 2021). Therefore, more research is needed to fully understand the impact of microplastics on different natural cycles, and one aspect is the microalgae degrade organic pollutants.

Microalgae-based biotechnology has been considered as a promising alternative solution to current activated sludge systems to better treat nutrients and pharmaceutical contaminants (Xiong et al. 2017a). Phytoremediation by microalgae as a form of solar-powered decontamination is considered an environmentally friendly, sustainable, cost-effective reclamation strategy and technology (Xiong et al. 2016). The biodegradation of environmental organic pollutants by algae has also been reported by some researchers (Xie et al. 2020; Xiong et al. 2020), indicating that algae have the potential to remove 
pollutants in wastewater. Bisphenol A (BPA) (an endocrine disruptor compound), which is used in the production of epoxy resin and polycarbonate (PC) plastics for various food and beverage packaging, baby bottles, and dental sealants (Staples et al. 1998). In recent years, positive outcomes were obtained for the remediation of BPA-contaminated aqueous systems by green algae, including Monoraphidium braunii (Gattullo et al. 2012), Chlamydomonas Mexicana and Chlorella vulgaris (Ji et al. 2014) and Desmodesmus sp.WR1 (Wang et al. 2017). However, reports on the effect of microplastics on the biodegradation of BPA during the cultivation of microalgae are still lacking.

Chlorella pyrenoidosa (C. pyrenoidosa) is a freshwater green algae, which is sensitive to pollutants in the aquatic environment and is usually used as a model organism in ecotoxicity tests ( $L i$ et al. 2019; Li et al. 2013; Liu et al. 2019; Zhao et al. 2017). Additionally, C. pyrenoidosa can accumulate and remove different pollutants in the aquatic environment (Peng et al. 2014; Wang et al. 2020; Wang et al. 2018). Therefore, in the present study, the ecotoxicological effects of different concentrations of BPA and PS microplastics on C.pyrenoidosa were evaluated according to the changes in microalgae growth. Moreover, further experiments were carried out to analyze the effects of PS on the biodegradation of BPA during microalgae cultivation. The kinetics of biodegradation of the BPA in combination and individually were also assessed.

\section{Materials And Methods \\ 2.1. Chemicals and reagents}

Bisphenol A (BPA) was purchased from Sigma-Aldrich (St. Louis, MO, USA), and was dissolved in methanol to obtain stock solutions. Polystyrene (PS) monodisperse microspheres (with the sizes of $9 \mu \mathrm{m}$ in diameter) were provided by Big Goose (Tianjin) Technology Co., Ltd (Tianjin, China) with an initial concentration of $2.5 \%(\mathrm{~W} / \mathrm{V})$, and the stock suspension was prepared by diluting with ultrapure water. BG11 medium was supplied by Qingdao Hope Biotechnology Co., Ltd. (Qingdao, China). All of the chemical reagents used were analytical pure grade.

\subsection{Algae cultivation}

Microalgae C.pyrenoidosa were obtained from the Institute of Hydrobiology, the Chinese Academy of Science. The culture medium (BG11) and the materials used for algal cultures were autoclaved at $121^{\circ} \mathrm{C}$ for 30 min before use. The algae cultivation was performed at $25 \pm 1^{\circ} \mathrm{C}$ under the illumination of $4,000 \mathrm{Ix}$ with a $12 / 12 \mathrm{~h}$ light/dark cycle, the flasks were manually shaken three times in the incubator every day.

\subsection{Growth inhibition test}

The growth inhibition of BPA on C.pyrenoidosa was determined by monitoring the cell growth. The algae suspension, at its exponential phase, was inoculated into $250-\mathrm{mL}$ flasks containing $100 \mathrm{~mL}$ of exposure medium at a density of $10^{5}$ cells $/ \mathrm{ml}$. BPA stock solutions were added in the autoclaved medium to achieve the initial concentrations $(1,10,20$ and $30 \mathrm{mg} / \mathrm{L})$, PS solution was added in the autoclaved medium to achieve the initial concentration $(5 \mathrm{mg} / \mathrm{L})$, the group without the PS and BPA algae 
suspension in the flasks served as the control group. Cultivation conditions were as described above, The optical density of algal suspension was carried out at $680 \mathrm{~nm}\left(\mathrm{OD}_{680}\right)$ by the Microplate Reader (Synergy $\mathrm{H} 1$ ). The algal concentration of . pyrenoidosa was measured by using a blood cell counting plate under a light microscope (Ding et al. 2017). The growth inhibition rate of C.pyrenoidosa was based on a correlation between $\mathrm{OD}_{680}$ and the microalgae density. The cell numbers of $C$.pyrenoidosa during the incubation was determined by the following equation:

Algal cell numbers of C.pyrenoidosa (cells $/ \mathrm{ml})=38.854 \times O D_{680}+0.2124(1)$

The growth inhibition rates were calculated as follows :

$$
I \%=\left(C_{0}-C\right) / C_{0}
$$

2

where $\mathrm{C}_{0}$ is the cell numbers of the algal suspension of the control group, $\mathrm{C}$ is the algal cell numbers of treated groups, and $1 \%$ is the growth inhibition rate.

\subsection{Analysis of photosynthetic pigment and chlorophyll fluorescence}

Photosynthetic pigments, namely, chlorophyll-a (Chl-a), chlorophyll-b (Chl-b) and total chlorophyll (Chl) was measured as described by Inskeep and Bloom (1985) (Inskeep and Bloom 1985). A volume of $40 \mathrm{~mL}$ microalgae culture was centrifuged at $5000 \mathrm{rpm}$ for $10 \mathrm{~min}$. The supernatant was then decanted, and the substrate was then mixed with $80 \%$ acetone and incubated at $4^{\circ} \mathrm{C}$ for $24 \mathrm{~h}$ in the dark. Next, the absorbances of the supernatant were measured at specified wavelengths of 647 and $664.5 \mathrm{~nm}$. Finally, the contents were computed using the following equations.

$$
\begin{aligned}
& C h l-a(m g / L)=12.63 * A 664.5-2.52 * A 647 \\
& C h l-b(m g / L)=20.47 * A 647-4.73 * A 664.5
\end{aligned}
$$

$$
\operatorname{Chl}(\mathrm{mg} / \mathrm{L})=17.95 * A 647+7.9 * A 664.5
$$

5

The pulse amplitude modulation fluorometer AquaPen AP 110-C (photosystem instrument, Czech Republic) equipped with FluorPen 1.0 software was used to measure the photosynthetic activity of C. pyrenoidosa. Fluorescence parameters were calculated according to the method described by Wang et al. (Wang et al. 2011). $F_{v} / F_{m}$ represents the maximal photochemical quantum yield and is a symbol for the light energy conversion efficiency of Photosystem II (PSII).

\subsection{Analysis of BPA by HPLC}


At $0,4,8,12$ and 16 days after treatment, $2 \mathrm{ml}$ of the algae suspension was collected and filtered by the polytetrafluoroethylene filter membrane. The concentration of BPA was monitored on a Dionex Ultimate 3000 HPLC). The HPLC system equipped with a binary pump with online solvent degasser, a diode array detector (DAD) and a TC-C18 column (Agilent, $5 \mu \mathrm{m}, 250 \times 4.6 \mathrm{~mm}$ ). The temperature of the column was maintained at $35^{\circ} \mathrm{C}$, The mobile phase consisted of $15 \%$ methanol and $85 \%$ water with $(0.2 \%)$ acetic acid $(\mathrm{V}: \mathrm{V})$ in a flow rate of $1.0 \mathrm{~mL} / \mathrm{min}$.

The removal kinetics of BPA were determined by the first-order model as follows:

$$
\ln C=-k t+\ln C 0
$$

6

$$
T_{1 / 2}=\ln 2 / k
$$

7

where $\mathrm{C}_{0}$ is the initial concentration of BPA at day $0, C$ is the concentration of BPA at time $t, k$ and $t$ are the removal rate constant $\left(\mathrm{d}^{-1}\right)$ and removal period in days, respectively.

\section{Results And Discussion}

\subsection{Growth inhibition of PS and BPA to the microalgae}

As showed in Fig. 1, The relationship between cells density and the concentration of BPA, growth inhibition and BPA in the absence and presence of $5 \mathrm{mg} / \mathrm{L}$ PS was investigated. This study found that both conditions have an adverse effect on the growth of the microalgae $C$. pyrenoidosa. Whether PS existed or not, the algae density decreased with the increase of BPA concentration. For instance, compared with the control group, in 1, 10, 20 and $30 \mathrm{mg} / \mathrm{L}$ BPA treatment, the growth inhibition rates were $12.52,12.85,21.75,41.85 \%$ at 8 days of exposure, respectively. These results were consistent with research results reported by $\mathrm{Ji}$ et al, who found that the growth of microalgal Chlorella vulgaris was significantly inhibited by BPA at concentration of $50 \mathrm{mg} / \mathrm{L}$ at the same exposure time, and the bigger inhibition ratio of growth at $50 \mathrm{mg} / \mathrm{L}$ of BPA treatment was higher than that under the $25 \mathrm{mg} / \mathrm{L}$ and 10 $\mathrm{mg} / \mathrm{L}$ BPA treatments in Chlamydomonas mexicana when exposed 7 days (Ji et al. 2014). A similar phenomenon was observed for the co-exposure of PS and BPA. For example, in $1 \mathrm{mg} / \mathrm{L} \mathrm{BPA}, 1 \mathrm{mg} / \mathrm{L} \mathrm{BPA}$ $+5 \mathrm{mg} / \mathrm{L}$ PS, $10 \mathrm{mg} / \mathrm{L} \mathrm{BPA}, 10 \mathrm{mg} / \mathrm{L} \mathrm{BPA}+5 \mathrm{mg} / \mathrm{L}$ PS treatment, the growth inhibition rate were 7.27, $9.52,13.48$ and $16.66 \%$ at 16 days of exposure, respectively. which indicated that the co-exposure of PS and BPA was more toxic to $C$. pyrenoidosa than when treated with BPA alone. Similarly, Yi et al. reported that the presence of PS $(0.55 \mu \mathrm{m})$ increased the toxicity of triphenyltin chloride (TPTCl) to the $C$. pyrenoidosa(Yi et al. 2019). The explanation was given in 3.2.

\subsection{Effects of BPA and PS on the $C$. pyrenoidosa photosystem}


The photosynthetic pigment is responsible for absorbing light energy and elevating the pigment to a higher energy state, which is known as an excited state. Photosynthetic pigments can be used as an indicator of the photosynthetic capacity of algae (Lu et al. 2018). Changes in the pigmentation system have been recognized as a defense mechanism under different types of stress conditions (Zhang et al. 2018). Common pigments in microalgae, such as chlorophyll (including chlorophyll a, chlorophyll b and total chlorophyll) and carotenoids, are usually considered to be indicators of cell adaptation. Chlorophyll plays an important role in photosynthesis. Specifically, chlorophyll plays a role in light harvesting, light energy conversion and energy transfer (Yang et al. 2020a). As observed in Table 1, Compared with the control group, the content of chlorophyll-a (Chl-a), chlorophyll-b (Chl-b) and total chlorophyll (Chl) in the cells increased after treatment for $16 \mathrm{~d}$. As the PS concentration increased, the C. pyrenoidosa chlorophyll content decreased, and the low concentration of BPA (1 $\mathrm{mg} / \mathrm{L} \mathrm{BPA})$ with $5 \mathrm{mg} / \mathrm{L}$ PS had the highest chlorophyll content. Although a decrease in chlorophyll content is common under stress-induced conditions, there are reports that when treated with low concentrations of pollutants, the chlorophyll content of C. pyrenoidosa increased and decreased at higher doses. Wan et al. Shows that when exposed to low concentrations of levofloxacin, the chlorophyll content in Microcystis flosaquae increased significantly, while the high concentration of levofloxacin reduced the chlorophyll content, which is due to the hermetic effect caused by antibiotic stress (Wan et al. 2014). A similar phenomenon was also observed in microalgae Scenedesmus obliquus when exposed to ofloxacin, the content of chlorophyll-a, chlorophyll-b, and chlorophyll, in the cells initially increased when the medium's ofloxacin was $10 \mathrm{mg} / \mathrm{L}$ (Yang et al. 2020a).

Fv/Fm indicates photosynthetic activity, which is widely used as an important indicator for monitoring algal photosystem II (PSII) activity (Yang et al. 2020b). As shown in Fig. 2, the Fv/Fm values of C. pyrenoidosa in the single BPA and BPA combined PS treatment at different concentrations were lower than that of the control group after $16 \mathrm{~d}$, indicating that the PS had a negative effect on the PSIl activity of C. pyrenoidosa. This negative influence was increased with concentration of the PS. The Fv/Fm values decreased by $0.2 \%, 5.1 \%, 12.1 \%, 6.9 \%, 9.5 \%$, and $15.6 \%$ for $1 \mathrm{mg} / \mathrm{L} \mathrm{BPA}, 1 \mathrm{mg} / \mathrm{L} \mathrm{BPA}+5 \mathrm{mg} / \mathrm{L} \mathrm{PS}, 1 \mathrm{mg} / \mathrm{L}$ BPA+100mg/L PS, $10 \mathrm{mg} / \mathrm{L}$ BPA, $10 \mathrm{mg} / \mathrm{L}+5 \mathrm{mg} / \mathrm{L} P S$ and $10 \mathrm{mg} / \mathrm{L} B P A+100 \mathrm{mg} / \mathrm{L} P S$, respectively. Overall, the above obtained Fv/Fm values of C. pyrenoidosa in $100 \mathrm{mg} / \mathrm{L}$ PS microplastics treatments were lower than those in the $5 \mathrm{mg} / \mathrm{L}$ PS microplastics treatments for both $1 \mathrm{mg} / \mathrm{L}$ and $10 \mathrm{mg} / \mathrm{L}$ of BPA exposure. This phenomenon can be attributed to the shading effect. A similar result was reported by Zhang et al. that PVC had significantly negative effects on chlorophyll content and PSIl activity of microalgae Skeletonema costatum (Zhang et al. 2017). Mao et al. also obtained the conclusion that the bigger inhibition ratio of $\mathrm{Fv} / \mathrm{Fm}$ at $100 \mathrm{mg} / \mathrm{L} \mathrm{PS}$ microplastics $(0.1 \mathrm{~mm})$ treatment was higher than that under the $10 \mathrm{mg} / \mathrm{L}$ and $50 \mathrm{mg} / \mathrm{L}$ PS microplastics (0.1 mm) treatments (Mao et al. 2018).

\section{Table 1}

Photosynthetic activity of $C$. pyrenoidosa under different conditions. 


\begin{tabular}{|c|c|c|c|c|c|c|c|}
\hline \multirow[t]{2}{*}{ Treatment } & $\begin{array}{l}1 \mathrm{mg} / \mathrm{L} \\
\text { BPA }\end{array}$ & $\begin{array}{l}1 \mathrm{mg} / \mathrm{L} \\
\mathrm{BPA}\end{array}$ & $\begin{array}{l}1 \mathrm{mg} / \mathrm{L} \\
\mathrm{BPA}\end{array}$ & $\begin{array}{l}10 \mathrm{mg} / \mathrm{L} \\
\text { BPA }\end{array}$ & $\begin{array}{l}10 \mathrm{mg} / \mathrm{L} \\
\text { BPA }\end{array}$ & $\begin{array}{l}10 \mathrm{~m} / \mathrm{L} \\
\mathrm{BPA}\end{array}$ & Control \\
\hline & & $\begin{array}{l}+5 \mathrm{mg} / \mathrm{L} \\
\text { PS }\end{array}$ & $\begin{array}{l}+100 \mathrm{mg} / \mathrm{L} \\
\text { PS }\end{array}$ & & $\begin{array}{l}+5 \mathrm{mg} / \mathrm{L} \\
\text { PS }\end{array}$ & $\begin{array}{l}+100 \mathrm{mg} / \mathrm{L} \\
\mathrm{PS}\end{array}$ & \\
\hline $\begin{array}{l}\text { Chl- } \\
\mathrm{a}(\mathrm{mg} / \mathrm{L})\end{array}$ & 37.96 & 48.98 & 36.58 & 43.43 & 43.48 & 37.49 & 36.01 \\
\hline $\begin{array}{l}\text { Chl- } \\
\text { b(mg/L) }\end{array}$ & 20.62 & 28.01 & 21.54 & 22.37 & 22.97 & 20.87 & 20.26 \\
\hline $\mathrm{Chl}(\mathrm{mg} / \mathrm{L})$ & 58.58 & 76.99 & 58.12 & 65.80 & 66.45 & 58.36 & 56.27 \\
\hline
\end{tabular}

\subsection{Effect of PS microplastics on the C.pyrenoidosa removal of BPA}

Due to its endogenous catabolic system, heterotrophic capacity, and role in carbon fixation and turnover, microalgae have the potential to remove organic pollutants (Xiong et al. 2017b). The removal kinetics of BPA by C.pyrenoidosa are shown in Fig. 3, after incubation for $16 \mathrm{~d}$, the removal efficiencies of BPA were $23.76 \%, 39.65 \%, 31.80 \%, 34.94,45.53 \%$ and $42.11 \%$ by incubation with this microalgae cells for $1 \mathrm{mg} / \mathrm{L}$ BPA, $1 \mathrm{mg} / \mathrm{L}$ BPA+5mg/L PS, $1 \mathrm{mg} / \mathrm{L}$ BPA+100mg/L PS, $10 \mathrm{mg} / \mathrm{L} \mathrm{BPA}, 10 \mathrm{mg} / \mathrm{L}$ BPA+5mg/L PS and 10 $\mathrm{mg} / \mathrm{L} B P A+100 \mathrm{mg} / \mathrm{L} P S$, respectively. A higher removal rate of BPA was observed at a lower exposure level with PS. Compared with the treatment without PS (exposure to $1 \mathrm{mg} / \mathrm{L} \mathrm{BPA}$ and $10 \mathrm{mg} / \mathrm{L} \mathrm{BPA}$ ), the BPA removal efficiency of lower PS exposure level $(5 \mathrm{mg} / \mathrm{L})$ increased by $15.89 \%$ and $10.59 \%$, respectively, suggesting that PS can accelerate the removal of BPA in the algae medium. These results are consistent with previous reports that the co-presence of polystyrene nanoplastic can enhance the degradation of ibuprofen in the medium of C.pyrenoidosa.

The kinetic analysis showed that the kinetic removal rate constant $\left(k, d^{-1}\right)$ of $1 \mathrm{mg} / \mathrm{L} B P A, 1 \mathrm{mg} / \mathrm{L}$ BPA+5mg/L PS, $1 \mathrm{mg} / \mathrm{L}$ BPA+100mg/L PS, 10mg/L BPA, 10mg/L BPA+5mg/L PS and $10 \mathrm{mg} / \mathrm{L} \mathrm{BPA}+100$ $\mathrm{mg} / \mathrm{L}$ PS ranged from 0.0149 to $0.0374 \mathrm{~d}^{-1}$, and the degradation half-life $\left(T_{1 / 2}, \mathrm{~d}\right)$ was calculated to be 18.53-46.52 d (Table 2). Furthermore, the removal of BPA via abiotic factors was evaluated through the addition of BPA to the medium without any C.pyrenoidosa inoculation. The initial concentration of BPA in the abiotic control did not show any change throughout $16 \mathrm{~d}$ (data not shown), thus, microalgae biomass is the main factor in the removal of BPA in this study, and the contribution of abiotic factors in the removal of BPA is negligible.

\section{Table 2}

Kinetic parameters of BPA degradation during $16 \mathrm{~d}$ of cultivation. 


\begin{tabular}{|c|c|c|c|c|c|c|}
\hline \multirow[t]{2}{*}{ Species } & \multirow[t]{2}{*}{$\begin{array}{l}1 \mathrm{mg} / \mathrm{L} \\
\text { BPA }\end{array}$} & \multirow{2}{*}{$\begin{array}{l}1 \mathrm{mg} / \mathrm{L} \\
\text { BPA } \\
+5 \mathrm{mg} / \mathrm{L} \\
\text { PS }\end{array}$} & \multirow{2}{*}{$\begin{array}{l}1 \mathrm{mg} / \mathrm{L} \text { BPA } \\
+100 \mathrm{mg} / \mathrm{L} \\
\text { PS }\end{array}$} & \multirow{2}{*}{$\begin{array}{l}10 \mathrm{mg} / \mathrm{L} \\
\text { BPA }\end{array}$} & \multirow{2}{*}{$\begin{array}{l}10 \mathrm{mg} / \mathrm{L} \\
\text { BPA } \\
+5 \mathrm{mg} / \mathrm{L} \\
\text { PS }\end{array}$} & \multirow{2}{*}{$\begin{array}{l}\text { 10mg/L BPA } \\
+100 \mathrm{mg} / \mathrm{L} \\
\mathrm{PS}\end{array}$} \\
\hline & & & & & & \\
\hline$k\left(d^{-1}\right)$ & 0.0149 & 0.0297 & 0.0199 & 0.0248 & 0.0374 & 0.031 \\
\hline $\mathrm{T}_{1 / 2}(\mathrm{~d})$ & 46.52 & 23.34 & 34.83 & 27.95 & 18.53 & 22.36 \\
\hline $\mathrm{R}^{2}$ & 0.9078 & 0.9058 & 0.8165 & 0.8871 & 0.8384 & 0.8544 \\
\hline $\begin{array}{l}\text { Total removal } \\
(\%)\end{array}$ & 23.76 & 39.65 & 31.80 & 34.94 & 45.53 & 42.11 \\
\hline \multicolumn{7}{|c|}{$\begin{array}{l}\text { k-kinetic removal rate constant }\left(\text { day }^{-1}\right) \text {. } \\
\mathrm{T}_{1 / 2} \text {-removal half-life (day). } \\
\mathrm{R}^{2} \text {-correlation coefficient. }\end{array}$} \\
\hline
\end{tabular}

\subsection{Proposed metabolic pathways of BPA in C.pyrenoidosa}

As can be seen from Fig. 4, the peak area of BPA decreased with the extension of the incubation time, and some new peaks with retention times different from that of peak-BPA were appeared after $4 \mathrm{~d}$, indicating that some intermediates were formed during the C.pyrenoidosa degradation of BPA. Potential transformation products of BPA were identified based on the mass-to-charge ratios $(\mathrm{m} / \mathrm{z})$, and their chemical structures were confirmed by the characteristic fragment ions. The mass spectra information after microalgal degradation is shown in Fig. S1. Based on these results and previous literature (Wang et al. 2017), the transformation pathways for BPA are proposed in Fig. 5. P1 was formed owing to oxidoreductase activity, and P1 further lost a molecule of $\mathrm{H}_{2} \mathrm{O}$ leading to the formation of P2. GarcíaRodríguez et al. revealed that phenolic compounds could be oxidized by oxidoreductases such as polyphenol oxidase and peroxidase (García-Rodríguez et al. 2015). In addition, oxidoreductase can catalyze the oxidative degradation of phenolic compounds (Taticchi et al. 2013). Therefore, our present study indicated that $C$.pyrenoidosa over-expressed oxidoreductase encoding genes to promote BPA oxidation to form hydroxyl groups on the benzene ring of BPA. P3 could be formed through another pathway via the action of oxidoreductase, indicating that the addition of a hydroxyl group to the P3. With the subsequent glycosyltransferase, P4 was further formed, a similar result was obtained for the biodegradation of BPA by the green alga Desmodesmus sp.WR1 (Wang et al. 2017). Hyung Ko et al (2006) demonstrated that glycosyltransferase was able to glycosylate phenolics (Hyung Ko et al. 2006). In 2003, Morohoshi et al. showed that BPA glycosylation resulted in the inability to detect the level of estrogenic activity in the yeast two-hybrid assay (Morohoshi et al. 2003). Therefore, our results also suggested that $C$.pyrenoidosa was able to transform BPA into non-toxic metabolites via glycosylation. P5 resulted from the cleavage of $-\mathrm{CH}_{2} \mathrm{OH}$, and the fragment $\mathrm{m} / \mathrm{z} 406$ (P6) corresponded to the subsequent loss of a hydroxyl group. 


\section{Conclusions}

The effects of PS on the toxic effects and biodegradation and removal of BPA in C.pyrenoidosa were reported in this study. In conclusion, The co-exposure of PS and BPA increased the growth inhibitory effect, decreased the chlorophyll content, and enhanced the removal efficiency of BPA in the medium. In addition, five intermediates were found based on the mass-to-charge ratios $(\mathrm{m} / \mathrm{z})$ in the biodegradation process. According to this, The degradation pathway of BPA by C.pyrenoidosa isp roposed in the presence of PS. More studies should be needed to explore the toxicity of microplastics and contaminants in the aquatic system to gain a better understanding of the detoxification mechanism behind the interactions of aquatic organisms.

\section{Declarations}

\section{Acknowledgments}

All authors contributed to the study conception and design. Material preparation, data collection and analysis were performed by Dandan He, Youmei Zeng, Guangming Zhou. The first draft of the manuscript was written by Dandan He and all authors commented on previous versions of the manuscript. All authors read and approved the final manuscript. This study was supported by the financial support from the Central Universities (No. XDJK2019C045). The authors have no competing interests to declare that are relevant to the content of this article.

\section{References}

Cincinelli A, Scopetani C, Chelazzi D, Lombardini E, Martellini T, Katsoyiannis A, Fossi MC, Corsolini S (2017) Microplastic in the surface waters of the Ross Sea (Antarctica): Occurrence, distribution and characterization by FTIR. Chemosphere 175: 391-400 doi:https://doi.org/10.1016/j.chemosphere.2017.02.024

Ding T, Yang M, Zhang J, Yang B, Lin K, Li J, Gan J (2017) Toxicity, degradation and metabolic fate of ibuprofen on freshwater diatom Navicula sp. J Hazard Mater 330: 127-134

doi:10.1016/j.jhazmat.2017.02.004

García-Rodríguez R, Romero-Segura C, Sanz C, Pérez AG (2015) Modulating oxidoreductase activity modifies the phenolic content of virgin olive oil. Food Chemistry 171: 364-369 doi:https://doi.org/10.1016/j.foodchem.2014.09.009

Gattullo CE, Bährs H, Steinberg CEW, Loffredo E (2012) Removal of bisphenol A by the freshwater green alga Monoraphidium braunii and the role of natural organic matter. Science of The Total Environment 416: 501-506 doi:https://doi.org/10.1016/j.scitotenv.2011.11.033 
Herbort AF, Sturm MT, Fiedler S, Abkai G, Schuhen K (2018) Alkoxy-silyl Induced Agglomeration: A New Approach for the Sustainable Removal of Microplastic from Aquatic Systems. Journal of Polymers and the Environment 26: 4258-4270 doi:10.1007/s10924-018-1287-3

Horton AA, Walton A, Spurgeon DJ, Lahive E, Svendsen C (2017) Microplastics in freshwater and terrestrial environments: Evaluating the current understanding to identify the knowledge gaps and future research priorities. Science of The Total Environment 586: 127-141

doi:https://doi.org/10.1016/j.scitotenv.2017.01.190

Hyung Ko J, Gyu Kim B, Joong-Hoon A (2006) Glycosylation of flavonoids with a glycosyltransferase from Bacillus cereus. FEMS Microbiology Letters 258: 263-268 doi:10.1111/j.1574-6968.2006.00226.x

Inskeep WP, Bloom PR (1985) Extinction Coefficients of Chlorophyll a and b in N,N-Dimethylformamide and $80 \%$ Acetone 1. Plant Physiology 77: 483-485 doi:10.1104/pp.77.2.483

Ji M-K, Kabra AN, Choi J, Hwang J-H, Kim JR, Abou-Shanab RAI, Oh Y-K, Jeon B-H (2014) Biodegradation of bisphenol $A$ by the freshwater microalgae Chlamydomonas mexicana and Chlorella vulgaris. Ecological Engineering 73: 260-269 doi:10.1016/j.ecoleng.2014.09.070

Klein S, Worch E, Knepper TP (2015) Occurrence and Spatial Distribution of Microplastics in River Shore Sediments of the Rhine-Main Area in Germany. Environmental Science \& Technology 49: 6070-6076 doi:10.1021/acs.est.5b00492

Li B, Lan Z, Wang L, Sun H, Yao Y, Zhang K, Zhu L (2019) The release and earthworm bioaccumulation of endogenous hexabromocyclododecanes (HBCDDs) from expanded polystyrene foam microparticles. Environmental Pollution 255: 113163 doi:https://doi.org/10.1016/j.envpol.2019.113163

Li Q, Wu YY, Wu YD (2013) Effects of fluoride and chloride on the growth of Chlorella pyrenoidosa. Water Science and Technology 68: 722-727 doi:10.2166/wst.2013.279

Lin W, Su F, Lin M, Jin M, Li Y, Ding K, Chen Q, Qian Q, Sun X (2020) Effect of microplastics PAN polymer and/or Cu2+ pollution on the growth of Chlorella pyrenoidosa. Environmental Pollution 265: 114985 doi:https://doi.org/10.1016/j.envpol.2020.114985

Liu L, Zhang S, Dai W, Bi X, Zhang D (2019) Comparing effects of berberine on the growth and photosynthetic activities of Microcystis aeruginosa and Chlorella pyrenoidosa. Water Science and Technology 80: 1155-1162 doi:10.2166/wst.2019.357

Lu T, Zhu Y, Xu J, Ke M, Zhang M, Tan C, Fu Z, Qian H (2018) Evaluation of the toxic response induced by azoxystrobin in the non-target green alga Chlorella pyrenoidosa. Environmental Pollution 234: 379-388 doi:https://doi.org/10.1016/j.envpol.2017.11.081

Mao Y, Ai H, Chen Y, Zhang Z, Zeng P, Kang L, Li W, Gu W, He Q, Li H (2018) Phytoplankton response to polystyrene microplastics: Perspective from an entire growth period. Chemosphere 208: 59-68 
Morohoshi K, Shiraishi F, Oshima Y, Koda T, Nakajima N, Edmonds JS, Morita M (2003) Synthesis and estrogenic activity of bisphenol A mono- and di- $\beta$-D-glucopyranosides, plant metabolites of bisphenol A. Environmental Toxicology and Chemistry 22: 2275-2279 doi:https://doi.org/10.1897/02-464

Peng F-Q, Ying G-G, Yang B, Liu S, Lai H-J, Liu Y-S, Chen Z-F, Zhou G-J (2014) Biotransformation of progesterone and norgestrel by two freshwater microalgae (Scenedesmus obliquus and Chlorella pyrenoidosa): Transformation kinetics and products identification. Chemosphere 95: 581-588 doi:https://doi.org/10.1016/j.chemosphere.2013.10.013

Staples CA, Dome PB, Klecka GM, Oblock ST, Harris LR (1998) A review of the environmental fate, effects, and exposures of bisphenol A. Chemosphere 36: 2149-2173 doi:https://doi.org/10.1016/S00456535(97)10133-3

Sussarellu R, Suquet M, Thomas Y, Lambert C, Fabioux C, Pernet MEJ, Le Goïc N, Quillien V, Mingant C, Epelboin Y, Corporeau C, Guyomarch J, Robbens J, Paul-Pont I, Soudant P, Huvet A (2016) Oyster reproduction is affected by exposure to polystyrene microplastics. Proceedings of the National Academy of Sciences 113: 2430 doi:10.1073/pnas.1519019113

Taticchi A, Esposto S, Veneziani G, Urbani S, Selvaggini R, Servili M (2013) The influence of the malaxation temperature on the activity of polyphenoloxidase and peroxidase and on the phenolic composition of virgin olive oil. Food Chemistry 136: 975-983 doi:https://doi.org/10.1016/j.foodchem.2012.08.071

Wan J, Guo P, Zhang S (2014) Response of the cyanobacterium Microcystis flos-aquae to levofloxacin. Environmental Science and Pollution Research 21: 3858-3865 doi:10.1007/s11356-013-2340-3

Wang F, Wang B, Qu H, Zhao W, Duan L, Zhang Y, Zhou Y, Yu G (2020) The influence of nanoplastics on the toxic effects, bioaccumulation, biodegradation and enantioselectivity of ibuprofen in freshwater algae Chlorella pyrenoidosa. Environmental Pollution 263: 114593

doi:https://doi.org/10.1016/j.envpol.2020.114593

Wang GH, Chen LZ, Hao ZJ, Li XY, Liu YD (2011) EFFECTS OF SALINITY STRESS ON THE PHOTOSYNTHESIS OF Wolffia arrhiza AS PROBED BY THE OJIP TEST. Fresenius Environmental Bulletin 20: $432-438$

Wang R, Diao P, Chen Q, Wu H, Xu N, Duan S (2017) Identification of novel pathways for biodegradation of bisphenol $A$ by the green alga Desmodesmus sp.WR1, combined with mechanistic analysis at the transcriptome level. Chemical Engineering Journal 321: 424-431 doi:10.1016/j.cej.2017.03.121

Wang S, Poon K, Cai Z (2018) Removal and metabolism of triclosan by three different microalgal species in aquatic environment. Journal of Hazardous Materials 342: 643-650 
Wu D, Wang T, Wang J, Jiang L, Yin Y, Guo H (2021) Size-dependent toxic effects of polystyrene microplastic exposure on Microcystis aeruginosa growth and microcystin production. Science of The Total Environment 761: 143265 doi:https://doi.org/10.1016/j.scitotenv.2020.143265

Xie P, Chen C, Zhang C, Su G, Ren N, Ho S-H (2020) Revealing the role of adsorption in ciprofloxacin and sulfadiazine elimination routes in microalgae. Water Research 172: 115475 doi:https://doi.org/10.1016/j.watres.2020.115475

Xiong J-Q, Kurade MB, Abou-Shanab RAI, Ji M-K, Choi J, Kim JO, Jeon B-H (2016) Biodegradation of carbamazepine using freshwater microalgae Chlamydomonas mexicana and Scenedesmus obliquus and the determination of its metabolic fate. Bioresource Technology 205: 183-190 doi:https://doi.org/10.1016/j.biortech.2016.01.038

Xiong J-Q, Kurade MB, Jeon B-H (2017a) Biodegradation of levofloxacin by an acclimated freshwater microalga, Chlorella vulgaris. Chemical Engineering Journal 313: 1251-1257 doi:10.1016/j.cej.2016.11.017

Xiong J-Q, Kurade MB, Kim JR, Roh H-S, Jeon B-H (2017b) Ciprofloxacin toxicity and its co-metabolic removal by a freshwater microalga Chlamydomonas mexicana. Journal of Hazardous Materials 323: 212-219 doi:https://doi.org/10.1016/j.jhazmat.2016.04.073

Xiong J-Q, Ru S, Zhang Q, Jang M, Kurade MB, Kim S-H, Jeon B-H (2020) Insights into the effect of cerium oxide nanoparticle on microalgal degradation of sulfonamides. Bioresource Technology 309: 123452 doi:https://doi.org/10.1016/j.biortech.2020.123452

Yang L, Ren L, Tan X, Chu H, Chen J, Zhang Y, Zhou X (2020a) Removal of ofloxacin with biofuel production by oleaginous microalgae Scenedesmus obliquus. Bioresource Technology 315: 123738 doi:https://doi.org/10.1016/j.biortech.2020.123738

Yang W, Gao X, Wu Y, Wan L, Tan L, Yuan S, Ding H, Zhang W (2020b) The combined toxicity influence of microplastics and nonylphenol on microalgae Chlorella pyrenoidosa. Ecotoxicology and Environmental Safety 195: 110484 doi:https://doi.org/10.1016/j.ecoenv.2020.110484

Yi X, Chi T, Li Z, Wang J, Yu M, Wu M, Zhou H (2019) Combined effect of polystyrene plastics and triphenyltin chloride on the green algae Chlorella pyrenoidosa. Environ Sci Pollut Res Int 26: 15011-15018 doi:10.1007/s11356-019-04865-0

Zhang C, Chen X, Wang J, Tan L (2017) Toxic effects of microplastic on marine microalgae Skeletonema costatum: Interactions between microplastic and algae. Environmental Pollution 220: 1282-1288 doi:https://doi.org/10.1016/j.envpol.2016.11.005 
Zhang L, Pei H, Chen S, Jiang L, Hou Q, Yang Z, Yu Z (2018) Salinity-induced cellular cross-talk in carbon partitioning reveals starch-to-lipid biosynthesis switching in low-starch freshwater algae. Bioresource Technology 250: 449-456 doi:https://doi.org/10.1016/j.biortech.2017.11.067

Zhao J, Cao X, Wang Z, Dai Y, Xing B (2017) Mechanistic understanding toward the toxicity of graphenefamily materials to freshwater algae. Water Research 111: 18-27

doi:https://doi.org/10.1016/j.watres.2016.12.037

\section{Figures}

\section{Figure 1}

The cells density of microalgae when exposed to BPA in the absence (a) and presence (c) of PS. The growth inhibition rate of microalgae when exposed to BPA in the absence (b) and presence (d) of PS.

\section{Figure 2}

The photosynthetic indices $\mathrm{F}_{\mathrm{v}} / \mathrm{F}_{\mathrm{m}}$ of $C$. pyrenoidosa when exposed to BPA and PS microplastics for $16 \mathrm{~d}$. 


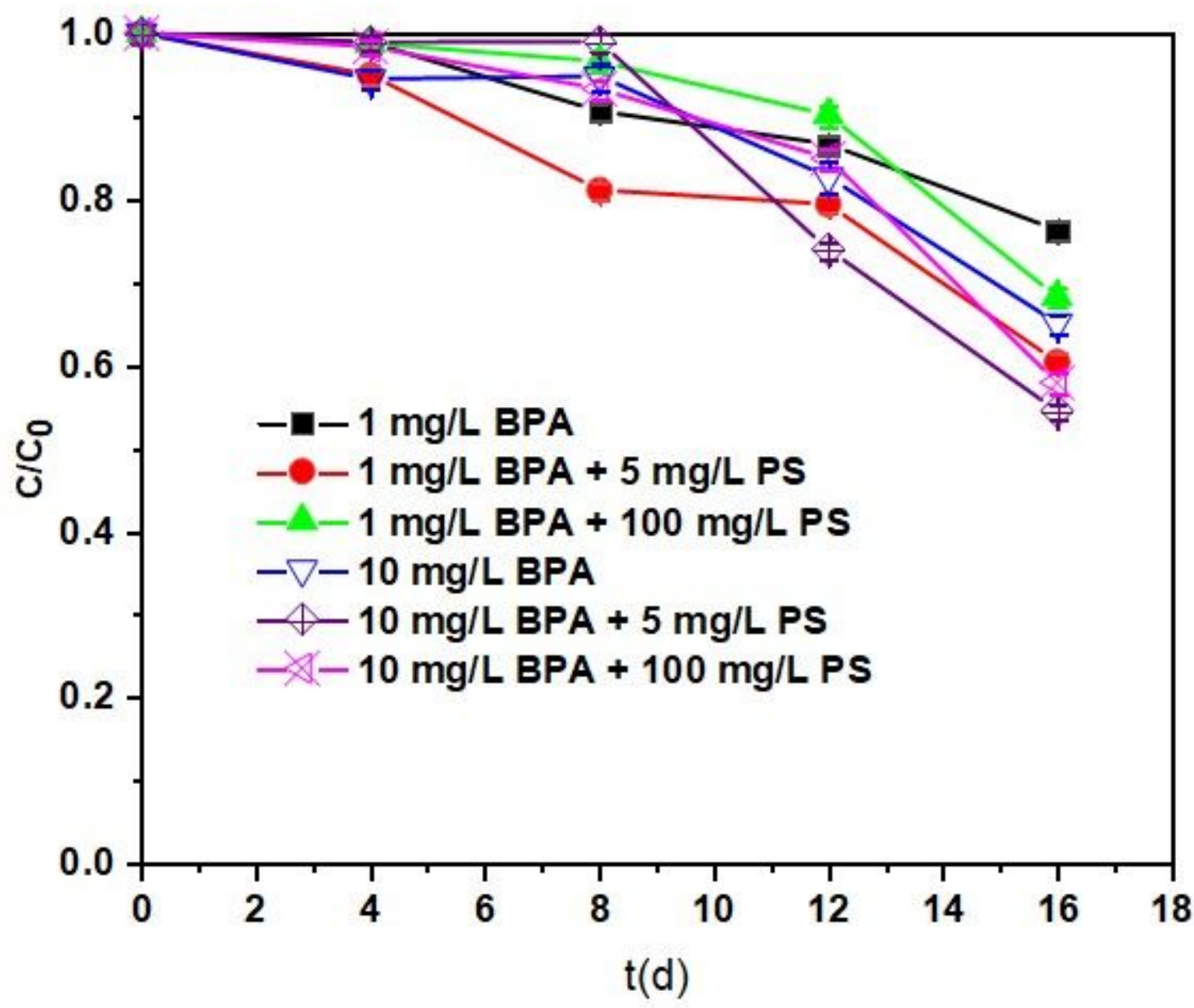

Figure 3

Effect of PS on the removal of BPA by incubation with C.pyrenoidosa. 


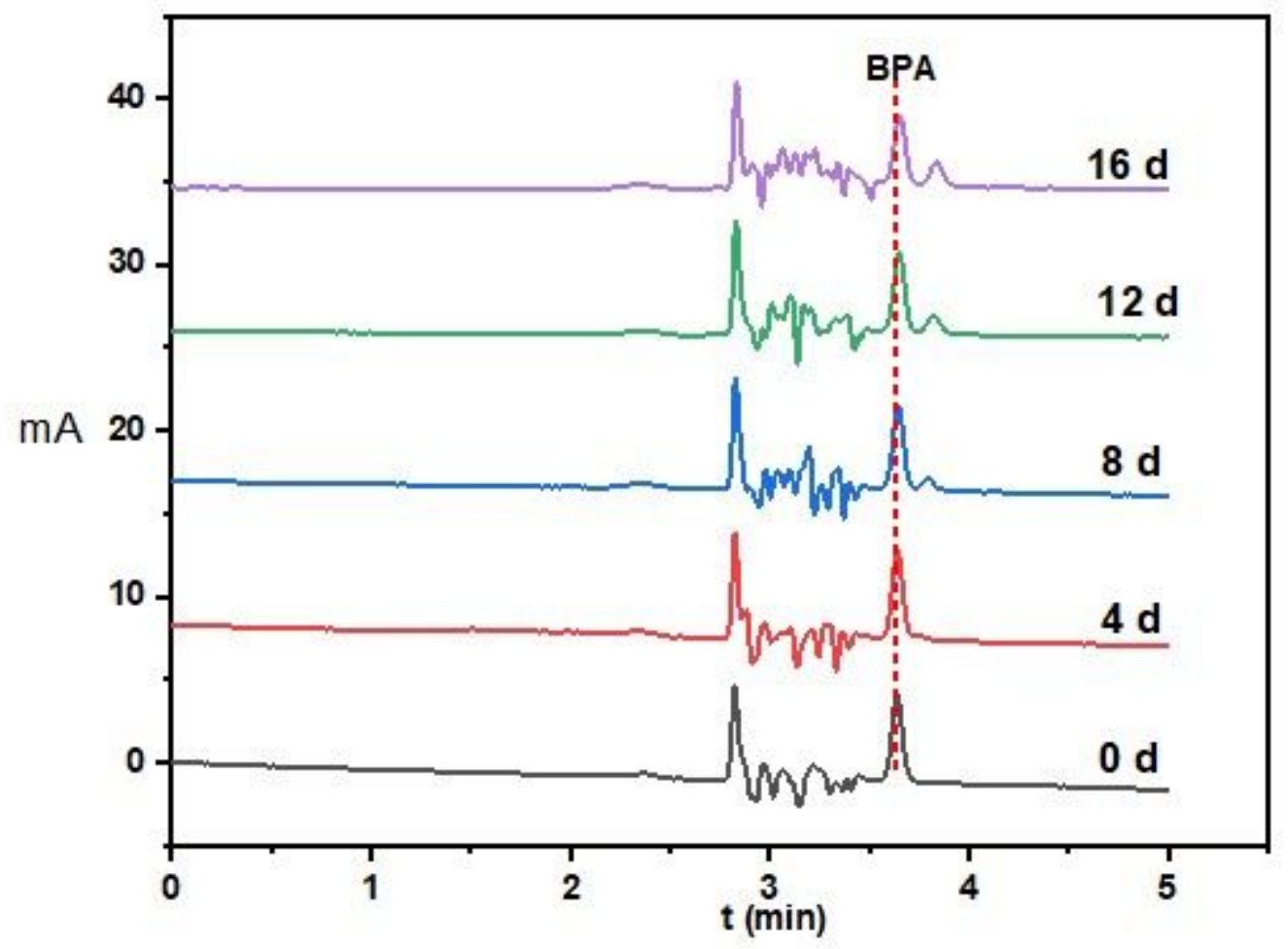

Figure 4

Chromatograms of BPA during the C.pyrenoidosa degradation processes.

Figure 5

Proposed transformation pathways of BPA by C.pyrenoidosa.

\section{Supplementary Files}

This is a list of supplementary files associated with this preprint. Click to download.

- SIV11.docx 